\title{
Specificity of Lactate for the Development of Competence in Haemophilus influenzae
}

\author{
By J. M. RANHAND* \\ Department of Microbiology, University of Cincinnati \\ College of Medicine, Cincinnati, Ohio 45219, U.S.A.
}

(Accepted for publication II October 1969)

\begin{abstract}
SUMMARY
A number of common carbohydrates and polyols were tested to see if they could replace the lactate requirement for the development of competence in cultures of Haemophilus influenzae. Pyruvate, fructose, and glucose, when tested in the presence of inosine, were slightly stimulatory. They gave respectively, 29, 25 and $13 \%$ of the control value obtained with inosine and lactate. Under similar test conditions, mannose, mannitol, galactose, sorbose, sorbitol, ribose, glucosamine, rhamnose, D (-) arabinose, L (+) arabinose, xylose and fucose were inactive.

In combination experiments, glucose, inosine and pyruvate, and fructose, inosine and pyruvate stimulated the development of competence to 50 to $70 \%$ of the inosine and lactate control value. Without inosine, the stimulation due to glucose and pyruvate, and fructose and pyruvate was 3 and $9 \%$, respectively.
\end{abstract}

\section{INTRODUCTION}

In an earlier report, Ranhand \& Herriott (1966) showed that the development of competence in Haemophilus influenzae was dependent upon the presence of both inosine and lactate during growth. Lactate could not be fully replaced by certain other three or four carbon acid-salts ( $\beta$-hydroxybutyrate, alanine, propionate and pyruvate) and inosine could not be fully replaced by other purines or pyrimidines (as free bases or nucleosides). This report extends the list of compounds that cannot replace lactate (when used in conjunction with inosine) and includes hexoses, pentoses and polyols.

\section{METHODS}

Organism. The organism used was Haemophilus influenzae strain RD described by Goodgal \& Herriott (196I).

Transforming deoxyribonucleic acid (DNA). Transforming DNA was prepared according to the method of Goodgal \& Herriott (196I) from H. influenzae organisms that were resistant to about $2 \mathrm{mg}$. streptomycin $/ \mathrm{ml}$.

Cultural conditions, competence development, and transformation. The methods used for growing organisms as well as the conditions used for the development of competence and transformation have been described previously (Ranhand \& Lichstein, I966).

Growth medium. Because of the nature of the experiments presented here the trypti-

* Present address: Laboratory of Microbiology, National Institute of Allergy and Infectious Diseases, Bethesda, Maryland 20014, U.S.A. 
case growth medium (TCM) described by Ranhand \& Lichstein (I966) was modified slightly. Glucose, an original component of the TCM, was omitted unless specifically added. Glycerol however, at $0.3 \%(\mathrm{v} / \mathrm{v})$ was added to the TCM even when all other carbohydrates listed in Table I were present.

Carbohydrates and polyols. All carbohydrates and polyols were obtained commercially. They were sterilized by filtration (Gelman membrane filters, $0 \cdot 2 \mu \mathrm{m}$. in pore size), and were used at a concentration of $0.13 \%(w / v)$. Glycerol was sterilized by autoclaving at $12 \mathrm{I}^{\circ}$ for $20 \mathrm{~min}$. Inosine was also sterilized by filtration, and was used at a concentration of $0.067 \%(\mathrm{w} / \mathrm{v})$.

\section{RESULTS AND DISCUSSION}

The bacterial cell wall may be the distinguishing feature between competent and non-competent bacterial cells. The experiments of Young, Spizizen \& Crawford (I963) and Young (1965) suggest that competent Bacillus subtilis cells (those capable of reacting with DNA) do have slight modifications in their cell-wall carbohydrate composition when compared to walls derived from similar but non-competent cells. The Gram-negative bacterial cell wall is a complex structure and its carbohydrate composition can be modified qualitatively by modifying the carbohydrates present in the growth medium (Weidel, Frank \& Martin, 1960; Nikaido, 1962). Lactate has been shown to be a precursor of carbohydrates (Krebs, Dierks \& Gascoyne, I964; Lardy, Paetkau \& Walter, I965) and therefore, has the potential of causing such modifications in the cell-wall composition of Haemophilus influenzae. In addition, competence can be destroyed with sodium periodate (Ranhand \& Lichstein, I966). It seemed reasonable therefore, to test whether simple carbohydrates could replace lactate's competence promoting activity.

When organisms were grown in the TCM containing inosine and pyruvate, inosine and fructose, or inosine and glucose, transformation (competence development) was stimulated 29,25 and I $3 \%$, respectively when compared to the inosine and lactate control value which was taken as $100 \%$ (Table I). Other hexoses, pentoses and polyols were inactive. The per cent transformation (no. of transformed organisms/ $\mathrm{ml} . \times$ Ioo divided by the no. of viable organisms $/ \mathrm{ml}$.) obtained with these latter compounds was no greater than the value obtained when inosine was used alone (about $0.01 \%$ ).

Pyruvate is only $30 \%$ as effective as lactate and not 80 to $90 \%$ as reported earlier (Ranhand \& Herriott, I966). This difference is probably due to glucose which was present in the TCM at that time. In other combination experiments employing inosine, glucose and pyruvate, or inosine, fructose and pyruvate, the stimulation of competence never exceeded 70 to $80 \%$ of the value obtained with inosine and lactate. Fructose and pyruvate, and glucose and pyruvate, in the absence of inosine, were respectively, 9 and $3 \%$ as effective as the inosine and lactate control.

When lactate, pyruvate, glucose and fructose were tested singly without inosine, lactate was still the best stimulator for the competent state. It was, however, only $9 \%$ as good as the inosine and lactate control value. It appears that the interactions between active or partially active compounds are synergistic in addition to the synergism observed earlier between inosine and lactate (Ranhand \& Herriott, 1966).

The data presented in this report show that no single carbohydrate, so far tested, 
can substitute for lactate. In addition, one partner of isomeric carbodydrates is partially active for the development of competence whereas the other member is not; for example, glucose and mannose, glucose and galactose, and fructose and sorbose. This result implies that either Haemophilus influenzae cannot interconvert these carbohydrates, or that the respective carbohydrates are impermeable to the bacteria. The notion that permeability may be limiting the effectiveness of the other carbohydrates listed in Table I was not tested. However, Olitzki \& Godinger (I958) showed that certain strains of $H$. influenzae can oxidize pentoses such as arabinose, xylose and ribose.

Table I. Effect of carbohydrates and polyols during growth on the development of competence in Haemophilus influenzae

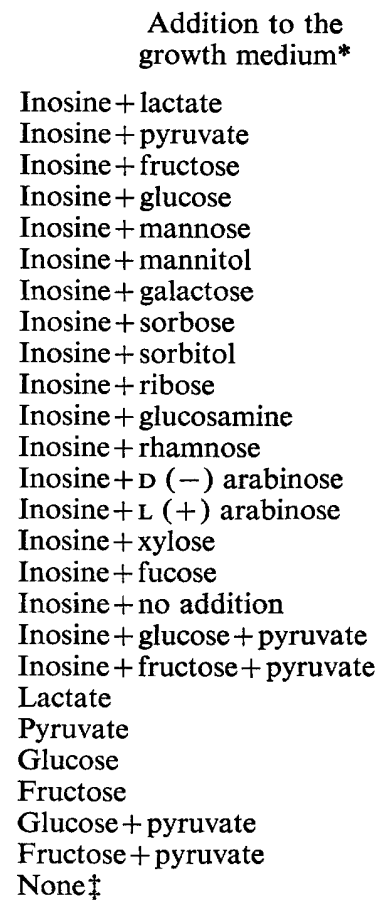

$\begin{array}{cc}\begin{array}{c}\text { Transformation } \\ \text { frequency } \\ (\%)\end{array} & \begin{array}{c}\text { Values relative to } \\ \text { inosine and lactate } \\ \text { control }(\%)\end{array} \\ \begin{array}{l}\text { I.4 } \\ 0.41\end{array} & (\text { I00) } \\ 0.35 & 29 \\ 0.18 & 25 \\ 0.027 & 13 \\ 0.012 & 2 \\ 0.021 & 1 \\ 0.032 & 2 \\ 0.012 & 2 \\ 0.023 & 1 \\ 0.014 & 2 \\ 0.006 & 1 \\ 0.008 & 0.4 \\ 0.004 & 0.6 \\ 0.007 & 0.3 \\ 0.007 & 0.5 \\ 0.01 & 0.5 \\ 0.67 & 0.7 \\ 1.0 & 48 \\ 0.13 & 71 \\ 0.013 & 9 \\ 0.002 & 0.9 \\ 0.0007 & 0.14 \\ 0.042 & 0.05 \\ 0.13 & 3 \\ 0.000065 & 9 \\ & 0.000046 \\ & \end{array}$

* All constituents were added at a concentration of $0.13 \%(w / v)$ except for inosine which was added at a concentration of $0.067 \%(\mathrm{w} / \mathrm{v})$.

$\dagger$ Transformation frequency equals the no. of transformed colonies $/ \mathrm{ml} \times$ Ioo divided by the no. of viable colonies $/ \mathrm{ml}$.

\$ TCM contained $0.067 \%$ adenosine without which the cells would not grow or grew poorly.

The role played by lactate in the development of competence still remains elusive. However, the data presented here do not rule out its conversion to some cell-wall carbohydrate.

This paper was taken in part from a dissertation submitted to the University of Cincinnati in partial fulfilment of the requirements for the $\mathrm{Ph} . \mathrm{D}$. degree and was supported in part by Public Health Service grant 5TI-GM I255 from the National 
Institutes of Health. This work was also supported in part by grants No. B $2595 \mathrm{G}$ and GB 6793 from the National Science Foundation and by a contract with the Office of Naval Research (NR-103-555) awarded to Dr H. C. Lichstein.

\section{REFERENCES}

Goodgal, S. H. \& Herriott, R. M. (1961). Studies on transformations of Hemophilus influenzae. I. Competence. Journal of General Physiology 44, I20I.

Krebs, H. A., Dierks, C. \& Gascoyne, T. (I964). Carbohydrate synthesis from lactate in pigeonliver homogenates. Biochemical Journal 93, 1 I 2.

LaRdy, H. A., PaetKau, V. \& Walter, P. (1965). Paths of carbon in gluconeogenesis and lipogenesis: the role of mitochondria in supplying precursors of phosphoenolpyruvate. Proceedings of the National Academy of Sciences of the United States of America 53, 1410.

NiKaIDo, H. (1962). Studies on the biosynthesis of cell-wall polysaccharide in mutant strains of Salmonella, 1. Proceedings of the National Academy of Sciences of the United States of America 48,1337 .

OlitzKI, A. L. \& Godinger, D. (1958). Influence of pentoses on the oxygen uptake of Haemophilus strains. Journal of Bacteriology 76, 160.

RANHAND, J. M. \& Herriott, R. M. (1966). Inosine and lactate: Factors critical during growth for development of competence in Haemophilus influenzae. Biochemical and Biophysical Research Communications 22, 591.

Ranhand, J. M. \& Lichstein, H. C. (I966). Periodate inhibition of transformation and competence development in Haemophilus influenzae. Journal of Bacteriology 92, 956.

Weidel, W., Frank, H. \& Martin, H. H. (I960). The rigid layer of the cell wall of Escherichia coli strain B. Journal of General Microbiology 22, 158.

YounG, F. E. (1965). Chemical composition of the cell walls of Bacillus subtilis during growth in different media. Nature, London 207, 104.

Young, F. E., Spizizen, J. \& Crawford, I. P. (1963). Biochemical aspects of competence in Bacillus subtilis transformation system. I. Chemical composition of cell walls. Journal of Biological Chemistry 238, 3119. 